\title{
Characterization of Wavelength Effect on Photovoltaic Property of Poly-Si Solar Cell Using Photoconductive Atomic Force Microscopy (PC-AFM)
}

\author{
Jinhee $\mathrm{Heo}^{\dagger}$ \\ Materials Characterization and Measurement Group, Korea Institute of Materials Science, Changwon 641-831, Korea
}

Received April 22, 2013; Revised May 1, 2013; Accepted May 2, 2013

\begin{abstract}
We investigated the effect of light intensity and wavelength of a solar cell device by using photoconductive atomic force microscopy (PC-AFM). The $\mathrm{POCl}_{3}$ diffusion doping process was used to produce a p-n junction solar cell device based on a Poly-Si wafer and the electrical properties of prepared solar cells were measured using a solar cell simulator system. The measured open circuit voltage $\left(\mathrm{V}_{\mathrm{oc}}\right)$ is $0.59 \mathrm{~V}$ and the short circuit current $\left(\mathrm{I}_{\mathrm{sc}}\right)$ is $48.5 \mathrm{~mA}$. Also, the values of the fill factors and efficiencies of the devices are $0.7 \%$ and approximately $13.6 \%$, respectively. In addition, PC-AFM, a recent notable method for nano-scale characterization of photovoltaic elements, was used for direct measurements of photoelectric characteristics in local instead of large areas. The effects of changes in the intensity and wavelength of light shining on the element on the photoelectric characteristics were observed. Results obtained through PC-AFM were compared with the electric/optical characteristics data obtained through a solar simulator. The voltage $\left(\mathrm{V}_{\mathrm{PC}}\right.$ AFM) at which the current was $0 \mathrm{~A}$ in the I-V characteristic curves increased sharply up to $1.8 \mathrm{~mW} / \mathrm{cm}^{2}$, peaking and slowly falling as light intensity increased. Here, $V_{\mathrm{PC}-\mathrm{AFM}}$ at $1.8 \mathrm{~mW} / \mathrm{cm}^{2}$ was $0.29 \mathrm{~V}$, which corresponds to $59 \%$ of the average $\mathrm{V}_{\mathrm{oc}}$ value, as measured with the solar simulator. Also, while light wavelength was increased from $300 \mathrm{~nm}$ to $1,100 \mathrm{~nm}$, the external quantum efficiency (EQE) and results from PC-AFM showed similar trends at the macro scale, but returned different results in several sections, indicating the need for detailed analysis and improvement in the future.
\end{abstract}

Keywords: Solar cell, Photoconductive AFM, External quantum efficiency, Wavelength, Photovoltaic effect

\section{INTRODUCTION}

With the recent increase in industrial and economical interest and investment in new and renewable energy, a great deal of development is occurring in the research and industrialization of photovoltaic devices, which is a representative clean form of energy production. The competition to develop a more efficient and cost-effective solar cell remains intensely. Research is especially lively in the area of analysis of the behavior of the photovoltaic effect on the nano scales for the development of tailored photoelectric materials and the development of competitive

${ }^{\dagger}$ Author to whom all correspondence should be addressed: E-mail: pidellis@kims.re.kr

Copyright $\odot 2013$ KIEEME. All rights reserved. This is an open-access article distributed under the terms of the Creative Commons Attribution Non-Commercial
License (http://creativecommons.org/licenses/by-nc/3.0) which permits unrestricted noncommercial use, distribution, and reproduction in any medium, provided the original work is properly cited. solar cell manufacturing processes through optimization.

The methods of analyzing the photoelectric effect, the basic principle behind the operation of the solar cell, and its mechanism, have been developed and improved together with the progress of photovoltaic power generation [1-4]. Among these methods, photoconductive atomic force microscopy (PC-AFM) is a type of SPM analysis method developed for property analysis of photovoltaic elements. With a composition based on the principles and devices of conductive AFM, it employs an additional attached light source to shine light onto the photovoltaic element. Normally, the light source is located beneath the specimen, and light is shone onto the specimen through a transparent conductive oxide. Through this device, the conversion efficiency of solar cells can be analyzed at the nano level, and visual analysis of phase separation, charge generation, charge transport, and charge collection can be performed. Also, using a monochrometer with wavelength modulation, this method is especially use- 
ful in studying the relationship between morphology, material composition, and light wavelength that impacts the photocurrent generation of the specimen [5-8].

In this study, PC-AFM, a recent noteworthy method for nanoscale characterization of photovoltaic elements, was used for direct measurements of the photoelectric characteristics in local instead of large areas. The effects of changes in the intensity and wavelength of light shining on the element on photoelectric characteristics were observed. Results gained through PC-AFM were compared with the electric/optical characteristics data gained through a solar simulator.

\section{EXPERIMENTS}

To investigate the effect of light intensity and wavelength of the solar cell device by using the PC-AFM, we prepared $p-n$ junction-structured poly-Si wafer-based solar cell devices. A 200 $\mathrm{nm}$-thick poly-Si wafer was heated in a diffusion furnace at temperatures up to $850^{\circ} \mathrm{C}$ with $\mathrm{POCl}_{3}$ to form a p-n junction on the surface of the wafer using the diffusion process. The thickness of the diffused $\mathrm{n}$-type region was about $300 \mathrm{~nm}$, and its sheet resistance was about $60 \Omega / \square$.

The dimensions of the fabricated solar cell were $2 \mathrm{~cm} \times 2 \mathrm{~cm}$, the thickness of the antireflection layer $\left(\mathrm{SiN}_{\mathrm{x}}\right)$ that was deposited by plasma enhanced chemical vapor deposition process was 76 $\mathrm{nm}$, and its refractive index was 1.97. After deposition of the $\mathrm{SiN}_{x}$ layer, the bottom and top electrodes were connected by screen printing with the silver paste, and the thicknesses of the bottom electrodes and the top electrodes were $60 \mu \mathrm{m}$ and $20 \mu \mathrm{m}$, respectively. For the formation of the ohmic contact for the electrodes, devices were annealed in $680^{\circ} \mathrm{C}$ with rapid thermal processing [9]. The electrical properties of prepared solar cells were measured using the K201 solar cell simulator system (McScience Inc., Korea), and the results are summarized in Table 1 . The average open circuit voltage $\left(\mathrm{V}_{\mathrm{oc}}\right)$ was $0.49 \mathrm{~V}$, and the average short circuit current $\left(\mathrm{I}_{\mathrm{sc}}\right)$ was $41.3 \mathrm{~mA}$. Also, the average values of fill factor and efficiency of the six devices were $0.7 \%$ and about $13.6 \%$, respectively. In addition, the external quantum efficiency (EQE) (which is the ratio of the number of charge carriers collected by the solar cell to the number of photons of a given energy shining on the solar cell from outside), was analyzed, and the results are shown in Fig. 5.

The following experiment was performed using the Seiko Instrument E-sweep SPM model, interfaced with an external light source and solar simulator to observe the effects of light intensity and wavelength on photoelectric effect characteristics (Fig. 1). First, a solar simulator was used to vary the intensity of light shining on the solar cell from $0 \mathrm{~mW} / \mathrm{cm}^{2}$ to $130 \mathrm{~mW} / \mathrm{cm}^{2}$ in $10 \mathrm{~mW} /$ $\mathrm{cm}^{2}$ increments and measure the resulting I-V characteristic curve. From this result, the $\mathrm{V}_{\mathrm{oc}}$ values corresponding to each level of light intensity were extracted. For PC-AFM analysis, light intensity was increased from $0 \mathrm{~mW} / \mathrm{cm}^{2}$ to $16 \mathrm{~mW} / \mathrm{cm}^{2}$, and the AFM system was used to measure the I-V characteristic curve. Here, the cantilever tip used as the electrode was a diamond tip doped with boron. The I-V measurements taken with PC-AFM were used to extract the voltage $\left(\mathrm{V}_{\mathrm{PC}-\mathrm{AFM}}\right)$, of which the current was $0 \mathrm{~A}$. This was presented against light intensity in a graph, and these results were compared with measurements from the solar simulator.

Also, to analyze the behavior of photoelectric characteristics in response to the wavelength of light shining on the solar cell device, the following measurements were made. Using the monochrometer attached to the PC-AFM, light wavelength was varied from $300 \mathrm{~nm}$ to $1,100 \mathrm{~nm}$ in $20 \mathrm{~nm}$ intervals, and the I-V characteristic curve was measured. Similar to the measurements described above, a diamond tip was used. The $\mathrm{V}_{\mathrm{PC}-\mathrm{AFM}}$ value at each wave-

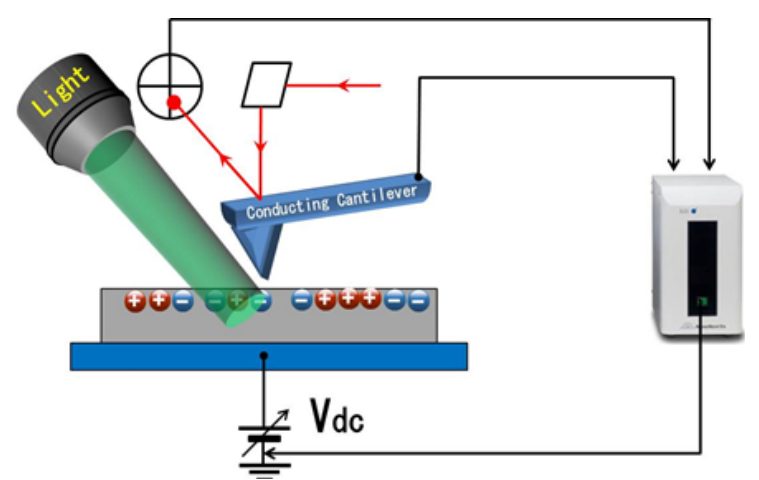

Fig. 1. Schematic of the photoconductive-AFM system. A diamond coated tip was used as an electrode, and the intensity and wavelength of light could be controlled.

length was extracted from the I-V measurements and presented in a graph (Fig. 5). These measurements were compared with EQE characteristics.

\section{RESULTS AND DISCUSSION}

The p-n junction-structured poly-Si-wafer-based solar cell devices were fabricated using a $\mathrm{POCl}_{3}$ diffusion process. The electrical properties of the prepared solar cell devices were measured, and the results are shown in Table 1 . The $\mathrm{V}_{\mathrm{oc}}$ is $0.59 \mathrm{~V}$ and the $\mathrm{I}_{\mathrm{sc}}$ is $48.5 \mathrm{~mA}$. Also, the values of the fill factors and efficiencies of the devices are $0.7 \%$ and approximately $13.6 \%$, respectively.

In addition, when light with a wavelength of $540 \mathrm{~nm}$ was used to irradiate the devices, the maximum values of the EQE (95\%) were attained. We verified that all of the devices had similar electrical and optical properties [9].

Figure 2 presents the I-V characteristic curves of poly-Si solar cells measured at various irradiation intensities. In the case where the voltage applied was zero, the $\mathrm{I}_{\mathrm{sc}}$ value linearly increased according to the light intensity. $\mathrm{V}_{\mathrm{oc}}$, the value of the voltage applied with the corresponding current being zero, remained between 0.5 and $0.6 \mathrm{~V}$, with its change indicated in Fig. 2(b).

The poly-Si-based solar cells were scanned using PC-AFM, and the topology and the current images were simultaneously obtained with 0 V DC bias under light irradiation as shown in Fig. 3. In the current-mapping image, the dark areas or spots indicate the flow of a more vertical current through the cell surface when compared with the bright area.

For analysis of the photoelectric effect in response to light intensity, light at $0.2,0.5,1,1.8,3,4,5.5,7.3,10,13$, and $16 \mathrm{~mW} /$ $\mathrm{cm}^{2}$ intensities was shone on the solar cell. Using a diamond tip as the electrode, the I-V characteristic curves were measured. From these results, the voltage $\left(\mathrm{V}_{\mathrm{PC}-\mathrm{AFM}}\right)$ at which the current was $0 \mathrm{~A}$ was extracted and is presented against light intensity in a graph (Fig. 4). Comparison of solar simulator analysis and PCAFM analysis results confirmed the following. First, in the solar simulator measurements, the $\mathrm{V}_{\mathrm{oc}}$ value increased dramatically when light intensity increased from $0 \mathrm{~mW} / \mathrm{cm}^{2}$ to $30 \mathrm{~mW} / \mathrm{cm}^{2}$. After this point, $V_{o c}$ increased at a low slope in response to increased light intensity, and tended to saturate. $\mathrm{V}_{\mathrm{oc}}$ at $30 \mathrm{~mW} / \mathrm{cm}^{2}$ was $0.47 \mathrm{~V}$, and the maximum $\mathrm{V}_{\mathrm{oc}}$ value was $0.58 \mathrm{~V}$.

On the other hand, in the PC-AFM measurements, $\mathrm{V}_{\mathrm{PC}-\mathrm{AFM}}$ increased sharply up to $1.8 \mathrm{~mW} / \mathrm{cm}^{2}$, peaking and slowly falling as light intensity increased. Here, $\mathrm{V}_{\mathrm{PC}-\mathrm{AFM}}$ at $1.8 \mathrm{~mW} / \mathrm{cm}^{2}$ was $0.29 \mathrm{~V}$, which corresponds to $59 \%$ of the average $V_{o c}$ value as measured with the solar simulator. It is believed that the $\mathrm{V}_{\mathrm{PC}-\mathrm{AFM}}$ value mea- 
Table 1. Electrical properties of poly-Si solar cell devices.

\begin{tabular}{cccccccc}
\hline $\begin{array}{c}\mathrm{V}_{\mathrm{m}} \\
(\mathrm{V})\end{array}$ & $\begin{array}{c}\mathrm{I}_{\mathrm{m}} \\
(\mathrm{mA})\end{array}$ & $\begin{array}{c}\mathrm{V}_{\mathrm{oc}} \\
(\mathrm{V})\end{array}$ & $\begin{array}{c}\mathrm{I}_{\mathrm{sc}} \\
(\mathrm{mA})\end{array}$ & $\begin{array}{c}\mathrm{P}_{\max } \\
(\mathrm{mW})\end{array}$ & $\mathrm{FF}$ & $\begin{array}{c}\text { Jsc } \\
\left(\mathrm{mA} / \mathrm{cm}^{2}\right)\end{array}$ & $\begin{array}{c}\text { Efficiency } \\
(\%)\end{array}$ \\
\hline \hline 0.49 & 41.3 & 0.59 & 48.5 & 20.0 & 0.7 & 32.9 & 13.6 \\
\hline
\end{tabular}
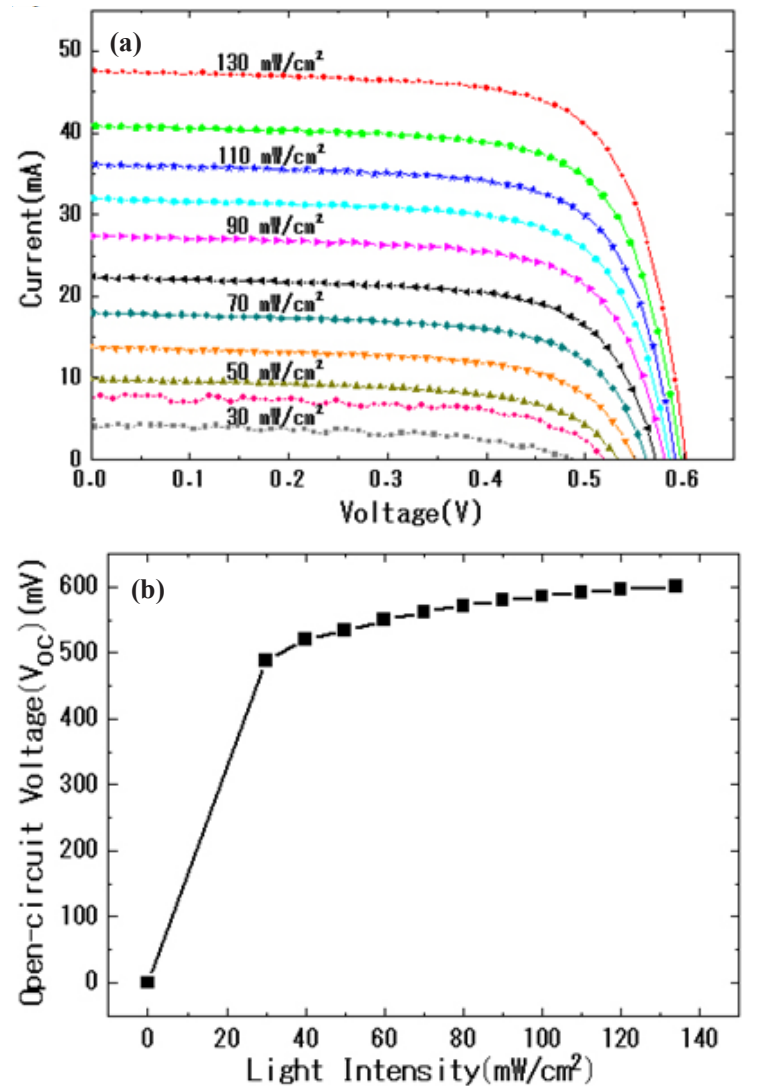

Fig. 2. (a) I-V characteristics of poly-Si solar cell devices and (b) open circuit voltage $\left(\mathrm{V}_{\mathrm{oc}}\right)$ with various light intensities.

sured with PC-AFM was low because the contact resistance in the areas of contact between the tip and surface of the specimen was larger than the ohmic contact resistance of the electrode used for the solar simulator measurements. It is also believed that the tendency for the $\mathrm{V}_{\mathrm{PC}-\mathrm{AFM}}$ values extracted from PC-AFM to decrease with increasing light intensity is because of the formation of a $\mathrm{SiO}_{2}$ oxidation layer formed on the Si surface of the solar cell when the current flows from this surface to the diamond tip [10-13]. Repeated I-V characteristic curve measurements were taken with the cantilever tip contacting the identical position on the specimen's surface. With the accumulation of the oxidation layer, contact resistance and voltage drop both increased. It is speculated that this resulted in the slow, downward trend of $\mathrm{V}_{\mathrm{PC}-\mathrm{AFM}}$.

The following measurements were then made to analyze photoelectric characteristics behavior in response to light intensity as measured with EQE and PC-AFM. After measuring the I-V characteristic curve while increasing the wavelength of light shining on the solar cell from $300 \mathrm{~nm}$ to $1,100 \mathrm{~nm}$ in $20 \mathrm{~nm}$ intervals, $\mathrm{V}_{\mathrm{PC}-\mathrm{AFM}}$ was extracted similarly to the previous analyses. Figure 5 presents the EQE and PC-AFM analysis results for the same wavelength range. Both measurements were made for wavelengths in the range of $300 \mathrm{~nm}$ to $1,100 \mathrm{~nm}$; also, between 300 $\mathrm{nm}$ and $700 \mathrm{~nm}$, it was seen that the EQE value and $\mathrm{V}_{\mathrm{PC} \text {-AFM }}$ value exhibited almost identical trends. However, $\mathrm{V}_{\mathrm{PC} \text {-AFM }}$ decreased

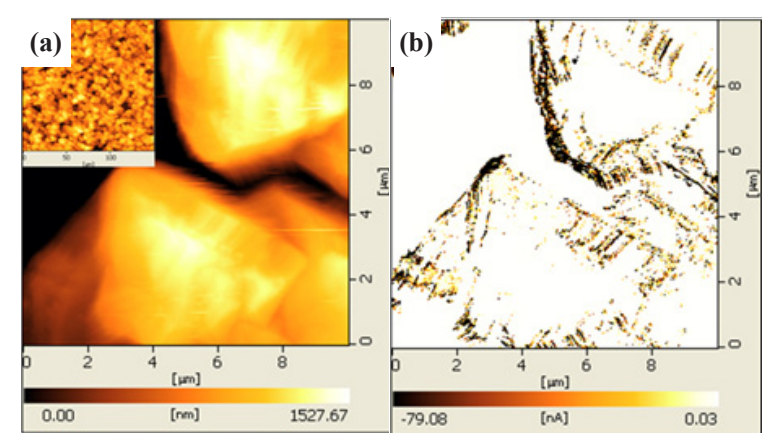

Fig. 3. (a) Topographic and (b) current mapping images of surface of solar cell devices which were obtained using conductive-AFM. Inset in (a) shows a $150 \times 150 \mu \mathrm{m}$ scanned topography image.

(a)

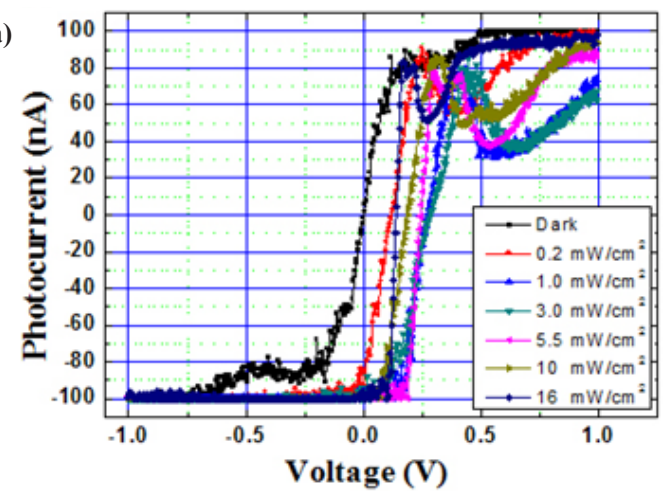

(b)

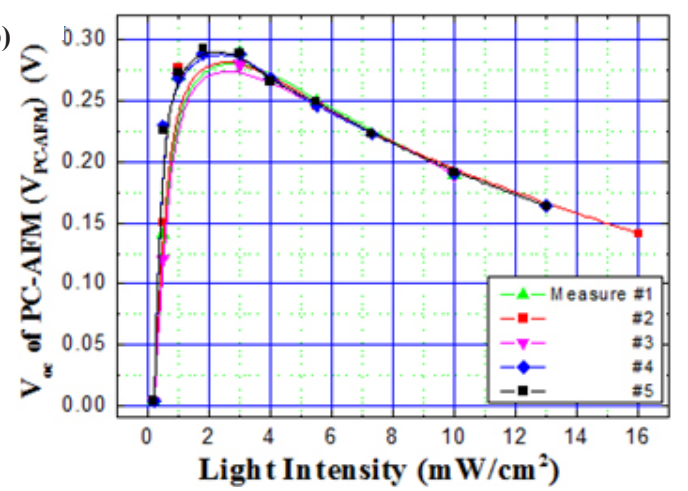

Fig. 4. (a) I-V characteristics and (b) $V_{\text {PC-AFM }}$ result from PC-AFM measurement with various light intensities.

by a larger rate than the $\mathrm{EQE}$ results beyond $700 \mathrm{~nm}$. Unlike the EQE results, $\mathrm{V}_{\mathrm{PC}-\mathrm{AFM}}$ showed oscillating behavior between $800 \mathrm{~nm}$ and $950 \mathrm{~nm}$

The cause for this difference in behavior between the two measurements has not yet been identified. Additional research is required on whether this effect on repeat I-V characteristic curve measurements is the result of variations in electric and optical characteristics between the local area where the tip contacts the specimen, mechanical vibrations, or unstable light factors. In order to overcome this limitation, a method of measurement wherein the wavelength of light shining on the specimen sweeps within a certain range allowing for direct extraction of $\mathrm{V}_{\mathrm{PC} \text {-AFM }}$ values would be required. However, despite these measurements, it has been confirmed through these results that the PC-AFM measurements were macro in scale, similar to the EQE analysis results. The potential of PC-AFM as a useful method of analysis in the measurement and analysis of photovoltaic characteristics 


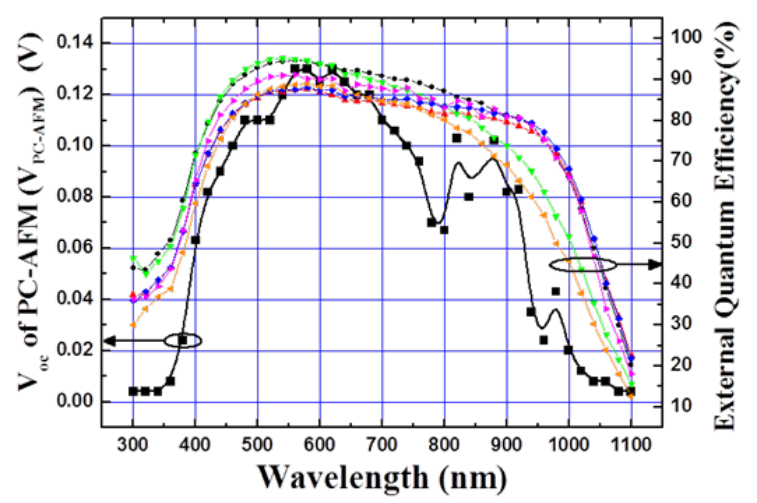

Fig. 5. External quantum efficiency (EQE) curves and $\mathrm{V}_{\mathrm{PC}-\mathrm{AFM}}$ value with light wavelength of poly-Si solar cell devices.

in response to wavelength variations of light at the nano scale was confirmed.

\section{CONCLUSIONS}

In this study, the $\mathrm{POCl}_{3}$ diffusion doping process was used to produce a p-n junction solar cell device based on a Poly-Si wafer. In terms of the electric characteristics of this solar cell, $\mathrm{V}_{\mathrm{oc}}$ was 0.59 and $\mathrm{I}_{\mathrm{sc}}$ was $48.5 \mathrm{~mA}$. The fill factor and conversion efficiency were $0.7 \%$ and $13.6 \%$, respectively. We used the solar simulator and PC-AFM methods to analyze the photovoltaic characteristics of this device. By comparing changes in $\mathrm{V}_{\mathrm{oc}}$ and $\mathrm{V}_{\mathrm{PC}-\mathrm{AFM}}$ from the PC-AFM method in response to increasing light intensity, we confirmed that in PC-AFM measurement, the contact resistance between the tip and surface of the specimen, and the generation of an oxidation layer from the current, impacted on the characteristic analysis.

In addition, while the light wavelength was increased from 300 $\mathrm{nm}$ to $1,100 \mathrm{~nm}$, the two measurements showed similar trends at the macro scale, but returned different results in several sections, indicating the need for detailed analysis and improvement in the future. Through such studies, it was confirmed that the PC-AFM method of analysis maintained a certain correlation with existing solar simulator research, and its advantage is that it is the only method of direct observation and comparison of the photovoltaic effect in specific local areas at the nano scale. This implies that PC-AFM could be indispensable in the analysis of photovoltaic mechanisms for new photovoltaic material development and process optimization required for future progress in solar cell technology.

\section{REFERENCES}

[1] A. Kueng, C. Kranz, A. Lugstein, E. Bertagnolli, B. Mizaikoff, Angew. Chem. Int. Ed. 42, 3238. (2003) [DOI: 10.1002/ anie.200351111].

[2] Azulay D, Balberg I, Chu V, Conde J P and Millo, “Current routes in hydrogenated microcrystalline silicon”, Phys. Rev. B 71, 113304 (2005) [DOI: 10.1103/PhysRevB.71.113304].

[3] C. Ionescu-Zanetti, A. Mechler, S. A. Carter, R. Lal, Adv. Mater. 16, 385. (2004) [DOI: 10.1002/adma.200305747].

[4] C.-G. Wu, S.-S. Chang, J. Phys. Chem. B 109, 825. (2005) [DOI: 10.1021/jp046259b].

[5] Behrang H. Hamadani, Suyong Jung, Paul M. Haney, Lee J. Richter and Nikolai B. Zhitenev "Origin of Nanoscale Variations in Photoresponse of an Organic Solar Cell”, Nano Lett., 10 (5), pp 1611-1617 (2010) [DOI: 10.1021/nl9040516].

[6] David C. Coffey and David S. Ginger, "Time-resolved electrostatic force microscopy of polymer solar cells", Nature Materials 5, 735-740 (2006) [DOI:10.1038/nmat1712].

[7] C. Groves, O. G. Reid and D. S. Ginger, "Heterogeneity in Polymer Solar Cells-Local Morphology and Performance in Organic Photovoltaics Studied with Scanning probe Microscopy", Acc. Chem. Res., 43, 612 (2010) [DOI: 10.1021/ar900231q].

[8] Behrang H. Hamadani, Suyong Jung, Paul M. Haney, Lee J. Richter and Nikolai B. Zhitenev, Nano Lett. 10 (5), 1611 (2010).

[9] Jinhee Heo and Youngmok Rhyim, "Study on the Correlation between the Photovoltaic Effect and the Defect Density at the Surface of a Poly-Si Solar Cell by Using Photoconductive Atomic Force Microscopy (PC-AFM) “, J. Korean Phys. Soc., 60, 9, 1322 1326 (2012) [DOI: 10.3938/jkps.60.1322].

[10] J. A. Dagata, J. Schneir, H. H. Harary, C. J. Evans, M. T. Postek, and J. Bennett, Appl. Phys. Lett., 56, 2001(1990) [DOI: 10.1063/1.102999].

[11] E. S. Snow, P. M. Campbell, and P. J. McMarr, Appl. Phys. Lett., 63, 749(1993) [DOI: 10.1063/1.109924].

[12] F. Perez-Murano, G. Adabal, N. Barniol, X. Aymerich, J. Servat, P. Gorostiza, and F. Sanz, J. Appl. Phys., 78, 6797 (1995) [DOI: 10.1063/1.360505].

[13] R. Garcia, M. Calleja, and F. Perez-Murano, Ap pl. Phys. Lett., 72, 2295(1998) [DOI: 10.1063/1.121340]. 